\title{
PTCH mutations in basal cell carcinomas from azathioprine-treated organ transplant recipients
}

\author{
CA Harwood,', NR Attard',2, P O' Donovan'2, P Chambers', CM Perrett', CM Proby', JM McGregor' \\ and P Karran ${ }^{2}$
}

'Centre for Cutaneous Research and Department of Dermatology, Institute of Cell and Molecular Science, Bart's and The London, Queen Mary School of Medicine and Dentistry, 4 Newark Street, London EI 2AT, UK; ${ }^{2}$ Mammalian DNA Repair Laboratory, Cancer Research UK, London Research Institute, Clare Hall Laboratories, Blanche Lane, South Mimms, Hertfordshire EN6 3LD, UK; ${ }^{3}$ Cancer Research UK Mutation Detection Facility, St James's

University Hospital, Leeds LS9 7TF, UK

\begin{abstract}
The immunosuppressant azathioprine is used to prevent graft rejection after organ transplantation. To investigate whether azathioprine-associated mutagenesis contributes to the high incidence of skin tumours in organ transplant recipients (OTRs), we analysed PTCH gene mutations in 60 basal cell carcinomas (BCC); 39 from OTRs receiving azathioprine and 21 from individuals never exposed to azathioprine. PTCH was mutated in 55\% of all tumours, independent of azathioprine treatment. In both the azathioprine and non-azathioprine groups, transitions at dipyrimidine sequences, considered to indicate mutation by ultraviolet-B radiation, occurred frequently in tumours from chronically sun-exposed skin. In BCC from non-sun-exposed skin of azathioprine-treated patients, there was an over-representation of unusual G:C to $A: T$ transitions at non-dipyrimidine sites. These were exclusive to the azathioprine-exposed group and all in the same TGTC sequence context at different positions within PTCH. Meta-analysis of 247 BCCs from published studies indicated that these mutations are rare in sporadic BCC and had never previously been reported in this specific sequence context. This study of post-transplant BCC provides the first indication that azathioprine exposure may be associated with PTCH mutations, particularly in tumours from non-sun-exposed skin.

British Journal of Cancer (2008) 99, 1276- 1284. doi:I0.1038/sj.bjc.6604665 www.bjcancer.com

(c) 2008 Cancer Research UK
\end{abstract}

Keywords: azathioprine; basal cell carcinoma; PTCH gene; immunosuppression; organ transplant recipients

Keratinocyte skin cancer (KSC) is the most common form of malignancy following solid organ transplantation. Up to $70 \%$ of fair-skinned solid organ transplant recipients (OTRs) will eventually develop KSC of whom two-thirds will have multiple tumours (Euvrard et al, 2003). Among these patients, the incidence of squamous cell carcinoma (SCC) is $>100$-fold higher than in the general population. They also have a significantly elevated $(>10$ fold) risk of basal cell carcinoma (BCC) (Euvrard et al, 2003). Epidemiological and limited molecular data implicate exposure to solar ultraviolet radiation (UVR) and the duration of immunosuppressive treatment in the development of transplant-related KSC (McGregor et al, 1997; Euvrard et al, 2003; Queille et al, 2007). The ultraviolet-B (UVB, $280-320 \mathrm{~nm}$ ) component of UVR is a known mutagen that causes transition mutations predominantly at dipyrimidine sequences (Brash et al, 1991). It also activates signalling pathways that enhance selection of neoplastic cells as well as suppressing immunity (de Gruijl, 1999; Dlugosz et al, 2002; Ullrich, 2005). Some commonly used immunosuppressants are carcinogens (IARC, 1987, 1990), although the extent to which impaired immune surveillance per se and long-term exposure to carcinogenic immunosuppressant drugs contribute to KSC in OTR is unknown.

\footnotetext{
*Correspondence: Dr CA Harwood; E-mail: caharwood@doctors.org.uk
} Received 6 June 2008; revised 27 August 2008; accepted 27 August 2008
The thiopurine pro-drug azathioprine (Aza) is a widely used immunosuppressant. Azathioprine causes 6-thioguanine (6-TG) to be incorporated into DNA where it can become methylated to produce a potentially promutagenic DNA lesion (Swann et al, 1996 ) or interact with UVA $(320-400 \mathrm{~nm})$. We have previously shown that, in the latter photochemical reaction, biologically relevant doses of UVA combine with DNA 6-TG and molecular oxygen to generate mutagenic reactive oxygen species and at least one novel and potentially promutagenic DNA lesion, guanine-6sulphonate $\left(\mathrm{GSO}_{3}\right)$ (O’Donovan et al, 2005; Karran and Attard, 2008). The combination of DNA 6-TG/UVA is mutagenic in cultured cells (O'Donovan et al, 2005). Photochemical DNA 6-TG damage also occurs in the clinical situation, and the skin of patients taking azathioprine is selectively hypersensitive to UVA (O'Donovan et al, 2005; Perrett et al, 2008). On the basis of these findings, we now examine the hypothesis that azathioprine may contribute directly to post-transplant cutaneous carcinogenesis.

Molecular analysis in KSC has largely centred on the TP53 gene, in which characteristic UVB signature mutations have been reported in up to $90 \%$ of sporadic SCC (Ziegler et al, 1994) and $60 \%$ of BCC (Ponten et al, 1997). Ultraviolet-B signature mutations have also been identified in the PTCH gene in BCCs (Gailani et al, 1996; Wolter et al, 1997; Lindstrom et al, 2006; Heitzer et al, 2007), and the mutational inactivation of $P T C H$, rather than TP53, is likely to be rate limiting for BCC. The PTCH tumour suppressor gene is located on chromosome $9 \mathrm{q} 22$, and germline mutations are 
found in the autosomal dominant condition nevoid BCC (Gorlin) syndrome (NBCCS, MIM 109400), in which patients typically develop numerous BCCs, usually from an early age (Hahn et al, 1996; Johnson et al, 1996). PTCH is also mutated in up to $70 \%$ of sporadic BCC (Gailani et al, 1996; Hahn et al, 1996; Johnson et al, 1996; Unden et al, 1996; Wolter et al, 1997; Aszterbaum et al, 1998; Ratner et al, 2001; Zhang et al, 2001; Kim et al, 2002; Reifenberger et al, 2005; Teh et al, 2005; Heitzer et al, 2007). Germline PTCH mutations in NBCCS are distributed throughout the entire gene and the majority cause protein truncation (Wicking et al, 1997). In BCC from NBCCS, the remaining PTCH allele is deleted or inactivated by mutation (Gailani et al, 1996). Up to $70 \%$ of acquired PTCH mutations are UVB-type G:C to A:T transitions or tandem mutations at dipyrimidine sequences (Lindstrom et al, 2006; Heitzer et al, 2007).

PTCH encodes a component of Hedgehog $(\mathrm{HH})$ signalling, a fundamental developmental signal transduction pathway that also controls epidermal cell proliferation. PTCH comprises 23 exons spanning approximately $50 \mathrm{~kb}$ and encodes a 1447-amino acid 12-transmembrane domain glycoprotein that binds Sonic hedgehog $(\mathrm{SHH})$, a secreted ligand regulating proliferation and patterning of multiple tissues during embryogenesis. Current models propose that PTCH inhibits $\mathrm{HH}$ signalling through interaction with the Smoothened (SMOH) protein (Bale and $\mathrm{Yu}, 2001)$ thereby repressing expression of the Gli1 and Gli2 transcription factors, which are themselves key mediators of $\mathrm{HH}$ signalling (Dahmane et al, 1997; Regl et al, 2002). PTCH repression of SMOH is relieved upon binding of SHH to PTCH resulting in the activation of Gli1 and Gli2 and several other genes including, for example, TGF-beta, Wnt, BCL-2 (Regl et al, 2002), basonuclin (Cui et al, 2004) and the forkhead transcription factors FOXMI (Teh et al, 2002) and FOXE1 (Eichberger et al, 2004). Temporally and spatially constrained SHH signalling regulates cyclic growth of hair follicle epithelium, but mutational inactivation of $P T C H$, or activating mutations in $S M O H$ or $\mathrm{SHH}$, leads to constitutive $\mathrm{HH}$ signalling (Unden et al, 1996; Oro et al, 1997; Xie et al, 1998; Bale and $\mathrm{Yu}, 2001)$. The resulting sustained proliferation drives the development of BCC and other follicle-derived tumours.

To investigate the role of azathioprine in the development of transplant-related BCC, we compared the PTCH mutation spectrum in sporadic BCC from patients immunosuppressed with azathioprine to the spectrum from individuals not exposed to azathioprine. The relative genetic homogeneity of BCC makes it a more tractable experimental system for molecular analysis than the genetically heterogeneous SCC (Quinn et al, 1994; Ashton et al, 2005; Purdie et al, 2007). In addition, the potentially rate-limiting nature of $P T C H$ inactivation is likely to be relevant to key mutational events in BCC. In this first study of post-transplant BCC, we report differences in the $P T C H$ mutational spectrum that we propose might reflect a direct influence of azathioprine exposure on BCC development.

\section{MATERIALS AND METHODS}

\section{Patients and samples}

Our institution has a dedicated OTR skin clinic in which over 1000 OTRs have been under surveillance since 1989 (Harwood et al, 2006; Ismail et al, 2006). Patients are seen within 12 months of transplantation and at least annually thereafter. Basal cell carcinomas from azathioprine-exposed individuals were obtained from this patient group. Thiopurine methyltransferase and thioguanine nucleotide levels, although useful for predicting acute myelotoxicity, were not specifically included in this study because all patients had been on azathioprine for at least 6 months and had stable haematological parameters. Non-azathioprineexposed individuals were recruited from among immunocompetent
(IC) individuals attending general dermatology clinics at the same institution. Clinical details including duration of transplantation, immunosuppressive drug history and site of BCC were documented.

Basal cell carcinomas were defined as sun-exposed (SE) lesions if they arose on chronically SE sites (head, neck, hands and forearms). Other sites not chronically SE or only intermittently SE were defined as non-sun exposed (NSE) and included locations such as trunk and proximal limbs. Basal cell carcinomas on NSE are more common in OTRs, accounting for up to one-third of OTR BCC compared with less than one-fifth of IC BCC (Kanitakis et al, 2003; Harwood et al, 2006).

All 60 tumours were histologically confirmed. Tumour tissue was collected at the time of surgery, immediately snap frozen and stored at $-70^{\circ} \mathrm{C}$. DNA was extracted by a standard phenolchloroform-isoamyl alcohol technique followed by ethanol precipitation. Matched whole blood samples were obtained for 32 tumours and DNA was extracted by Nucleon DNA extraction kit (Scotlab, Lanarkshir, UK).

Ethical approval for this study was obtained from the East London and City Health Authority Ethics Committee. All patients provided written informed consent. The study was conducted according to the Declaration of Helsinki Principles.

\section{Mutation detection}

An initial mutation screening of exons 2-23 of PTCH was performed by melting curve analysis (MCA). This study used MCA as a primary mutation screening technique before DNA sequencing. This technique has earlier been shown to be a highly sensitive and specific method for mutation screening (Reed and Wittwer, 2004). Melting curve analysis generates qualitative data; therefore, the nature and locations of mutations was confirmed by DNA sequencing.

PCR was performed in the presence of LCGreen + , a doublestranded DNA-binding dye. PCR products were then melted on a LightScanner (Idaho Technologies, Salt Lake City, UT, USA). As the DNA melted, LCGreen + was released and there was a reduction in the level of fluorescence. Measurement of differences in the rate of change of fluorescence allowed detection of variations. Melting curve analysis results were scored by two independent scientists. Exon $1 \mathrm{~B}$ was not screened as the high $\mathrm{G}+\mathrm{C}$ content of this exon did not permit reliable analysis. Amplification and analysis of exons 2 and 23 in two fragments resulted in the generation of less complex melting profiles and therefore increased the sensitivity of MCA for these exons.

PCRs for MCA contained PCR buffer, $200 \mu \mathrm{M}$ dNTPs, $\mathrm{MgCl}_{2}$ as required (Supplementary Table 1 online), $1 \mu$ l LCGreen + (all Idaho Technologies), $0.25 \mathrm{U}$ of ThermoStart Taq polymerase (ABgene, Epsom, UK), primers as required, DMSO to a final concentration of $5 \%, 20 \mathrm{ng}$ of genomic DNA and sufficient water to make a final volume of $10 \mu$ l. Thermal cycling conditions were $95^{\circ} \mathrm{C}$ for $12 \mathrm{~min}$ to activate the Taq polymerase followed by 45 cycles of $94^{\circ} \mathrm{C}$ for $10 \mathrm{~s}$, annealing temperature (Supplementary Table 1 online) for $15 \mathrm{~s}$ and $72^{\circ} \mathrm{C}$ for $15 \mathrm{~s}$. To ensure maximum incorporation of LCGreen + into double-stranded amplified DNA, PCR products were heated to $94^{\circ} \mathrm{C}$ for $30 \mathrm{~s}$ and allowed to cool to $25^{\circ} \mathrm{C}$ at $0.1^{\circ} \mathrm{C}$ per second. PCR primer sequences and amplification conditions for each amplified fragment are shown in Supplementary Table 1 online. Variations detected by MCA were then fully characterised by DNA sequencing with a version 1.1 BigDye Terminator kit (Applied Biosystems, Warrington, UK) and analysed on an Applied Biosystems 3730 .

DNA and protein numbering was based on the following GenBank accessions: genomic DNA AL161729, cDNA NM_000264 and protein NP_000255. Mutations and single-nucleotide polymorphisms were compared with the GenBank database, the 
Table I Clinical details of patients and tumours

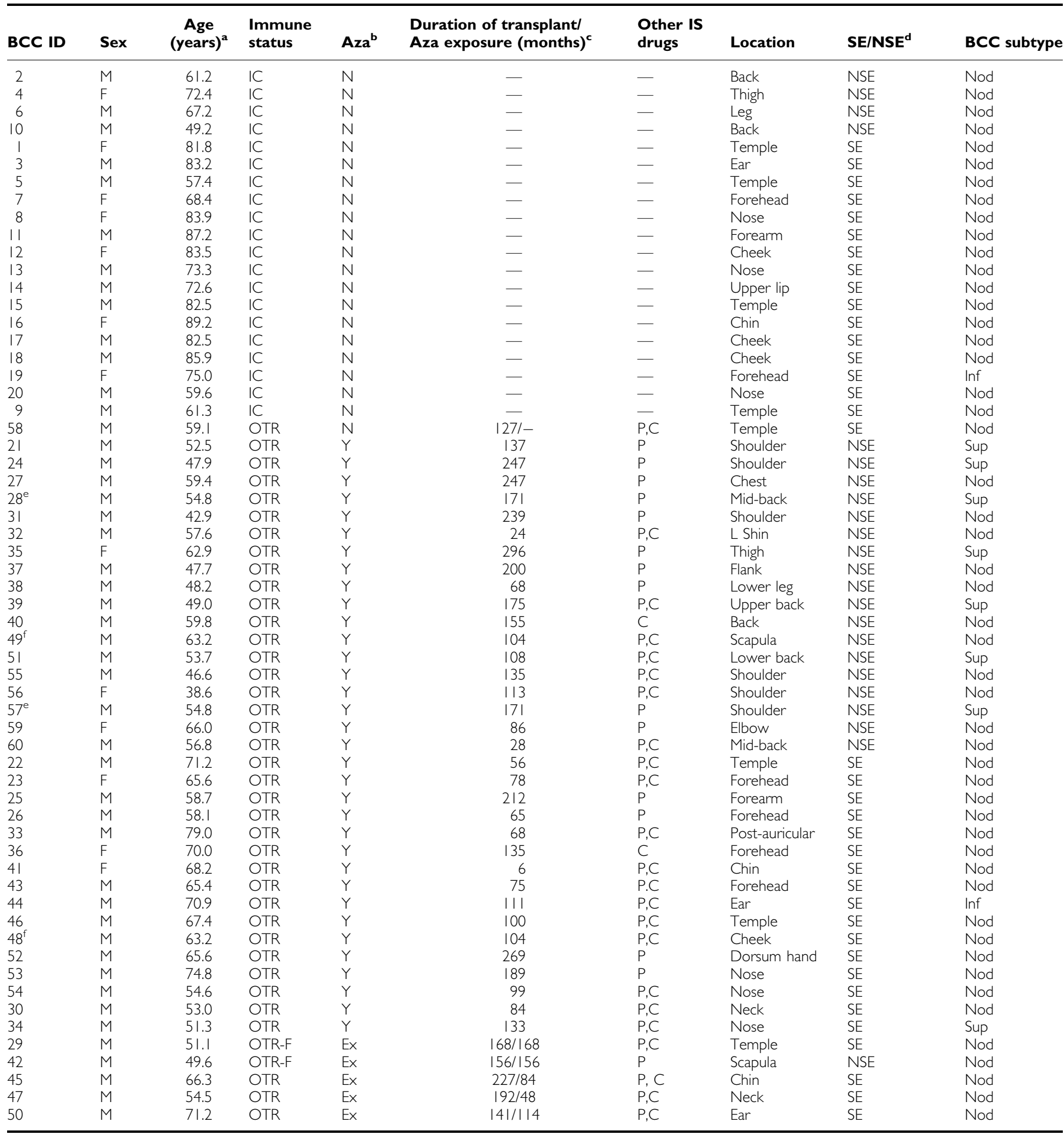

Aza = azathioprine exposure; $B C C=$ basal cell carcinoma; $C=$ ciclosporin; $C I S=$ squamous carcinoma in situ (Bowen's disease); Ex = previously on azathioprine; $F=$ female; $I C=$ immunocompetent individual; inf = infiltrative $B C C ; I S=$ immunosuppressive; $M=$ male; nod = nodular $B C C ; N S E=$ non-sun-exposed site; $P=$ prednisolone; sample $I D$ = sample identification number; $S C C=$ squamous cell carcinoma; $S E=$ chronically sun-exposed site; sup = superficial BCC; OTR = organ transplant recipient; OTR-F = failed organ transplant. ${ }^{\mathrm{a}} \mathrm{Age}$ at removal of BCC (years). ${ }^{\mathrm{b}}$ Azathioprine exposure: Y, currently exposed; Ex, previously exposed to azathioprine, but not at the time of BCC removal; pt 29, transplant failed and off azathioprine for 3 years before removal of BCC (but maintained on ciclosporin and prednisolone); pt 45, off azathioprine for more than 10 years before removal of BCC; pt 47, off azathioprine for at least 8 years before removal of BCC; pt 50, off azathioprine for at least 2 years before removal of BCC. ${ }^{\mathrm{C}}$ For patients on azathioprine at the time of diagnosis, the duration of transplantation is equivalent to the duration of azathioprine exposure. For patients previously exposed but off azathioprine at the time of BCC removal, the duration of previous azathioprine exposure was approximately 168 months, 84 months, 48 months and II 4 months for patient nos. $29,45,47$ and 50, respectively. 'Anatomical location of a BCC was classified as 'sun-exposed' if it arose on a chronically UV-exposed site (head and neck, dorsum hands and forearms). BCCs arising on rarely or only intermittently sun-exposed sites were grouped together as 'non-sun-exposed'. 'Samples 28 and 57 were from the same individual; although apparently clinically separate, the finding of an identical PTCH mutation raises the possibility that they may represent a single lesion. ${ }^{\mathrm{f}} \mathrm{Samples} 48$ and 49 were from the same individual. 
PTCH Mutation Database (www.cybergene.se/PTCH/) and relevant publications not yet entered on the PTCH Mutation Database at the time of this analysis (specifically Heitzer et al (2007)). The effect of intronic mutations on splicing was predicted using software at http://www.fruitfly.org/seq_tools/splice.html. Effect of exonic mutations on exonic splice enhancers was predicted using software at http://rulai.cshl.edu/tools/ESE/

\section{Statistical analysis}

Statistical analysis was performed in Stata (Stata Corp 2003 Statistical Software: Release 9.0: College Station, TX, USA). Formal comparisons were made using logistic regression where possible. Multiple samples from the same individual could not be considered independent. Model-based variance estimates were therefore inappropriate, and robust sandwich estimates of variance were used instead. For comparisons of proportions of those with the unique G:C to A:T transitions at non-dipyrimidine sites, the numbers were too small to allow the use of logistic regression. In this case, and others where numbers were not sufficient, the Fisher's exact test was used. To preserve independence, we used Fisher's exact test on the number of individuals rather than on the number of samples.

\section{RESULTS}

\section{Patients and tumours}

Sixty BCCs from 58 individuals (38 OTRs and 20 IC individuals) were analysed in this study. Detailed patient information is presented in Table 1. (a) Azathioprine-exposed individuals (Aza group) comprised 37 OTRs with BCC (30 males, 7 females). The mean age at sampling was 58.8 years (38.6-79.0 years) and mean duration of transplantation was 134 months (range 6-296 months). Thirty-two individuals were currently receiving systemic immunosuppression with azathioprine and five had previously received azathioprine, before BCC diagnosis. Additional immunosuppressants included ciclosporin $(n=24)$ and prednisolone $(n=36)$. Twenty of these azathioprine-exposed OTRs had a previous history of KSC, 12 out of 37 (32.4\%) with at least one BCC.

(b) Non-azathioprine-exposed subjects (non-Aza group) included 20 IC individuals ( 13 men, 7 women; mean age 73.9 years) and one OTR (males; age 69.4 years; duration of transplant 127 months), never exposed to azathioprine. This OTR had three prior BCCs but none of the IC individuals had a history of KSC.

Overall, therefore, 39 tumours were from the Aza group in which two patients each had two separate tumours. There were 21 tumours from non-Aza individuals. The 60 BCCs comprised 50 nodular, 8 superficial and 2 infiltrative/morphoeic subtypes.

\section{Azathioprine exposure and the frequency and location of PTCH mutations}

There were no germline $\mathrm{PTCH}$ mutations in any of the individuals examined. PTCH mutations were detected in 33 out of $60(55 \%)$ BCC overall. Azathioprine exposure did not influence this frequency. A total of 17 mutations were found in 11 out of 21 (52\%) non-azathioprine-exposed BCCs (Table 2) vs 27 mutations from 21 out of 39 (54\%) azathioprine-exposed BCCs (Table 3).

Table 2 PTCH mutations in BCC from non-azathioprine-exposed individuals

\begin{tabular}{|c|c|c|c|c|c|c|}
\hline BCC ID & $\begin{array}{l}\text { Exon/intronic } \\
\text { position }\end{array}$ & $\begin{array}{l}\text { Variation in } \\
\text { genomic DNA }{ }^{a, b}\end{array}$ & Sequence context & $\begin{array}{l}\text { Variation in } \\
\text { protein }^{c}\end{array}$ & $\begin{array}{l}\text { PTCH } \\
\text { domain }\end{array}$ & Effect $^{d}$ \\
\hline 3 & IVSI8+5 & g. $102844 \mathrm{G}>\mathrm{T}$ & tgagtgt & - & - & Possible effect on splicing \\
\hline 5 & Exon 14 & g.91889 G>T & gctgagc & p. E680X & ICL3 & Nonsense mutation \\
\hline \multirow[t]{2}{*}{7} & Exon 12 & g.84793_8480I del & ttcccgctctgc ggg & $\begin{array}{l}\text { P. P568_R570 } \\
\text { delins R }\end{array}$ & TM5 & 3-amino-acid deletion, arginine at position 568 \\
\hline & IVS5-I & g.80263 G>A & gcagagg & - & - & mRNA splicing \\
\hline 9 & IVS8 and exon 9 & g.82662_82677del & accacaggtggttcatcagagt & See below ${ }^{f}$ & - & See below ${ }^{f}$ \\
\hline \multirow[t]{2}{*}{12} & Exon 15 & g.93597 C>T & cacccag & p. Т807Т & ECL2 & $\begin{array}{l}\text { Silent variant; possible effect on exonic splice } \\
\text { enhancer }\end{array}$ \\
\hline & & g.93598 C>T & Single tandem mutation & p. Q808X & & Nonsense mutation \\
\hline \multirow[t]{2}{*}{14} & Exon 3 & g.75। $33 \mathrm{C}>\mathrm{T}$ & ctccagg & p. Q184X & ECLI & Nonsense mutation \\
\hline & Exon 15 & g.93653 del T & gtttcag & p. F826S fs $\times 4$ & ECL2 & Stop codon at position 829 \\
\hline 15 & Exon 9 & $\begin{array}{l}\text { g.82774 del G } \\
\text { (homozygous) }\end{array}$ & cgcgtgg & p. $V 442 W$ fs $X 14$ & TM2 & Stop codon at position 455 \\
\hline \multirow[t]{2}{*}{16} & Exon 16 & $98986 A>G$ & tcgacat & p. D898G & ECL2 & $\begin{array}{l}\text { Missense mutation; possible effect on exonic } \\
\text { splice enhancers }\end{array}$ \\
\hline & IVS9+I & g.82798 G>A & atggtaa & - & - & RNA splicing \\
\hline 17 & Exon 18 & g. $10258 \mid$ del G & cgagtat & p. E970D fs $\times 25$ & ECL2 & Stop codon at position 994 \\
\hline \multirow[t]{2}{*}{19} & IVS21-27 & g. III $502 \mathrm{C}>\mathrm{T}$ & acacttt & - & - & See below ${ }^{\mathrm{e}}$ \\
\hline & IVS8-6 & g.82660 C>A & $\operatorname{tgaccac}$ & - & - & No effect on splicing predicted \\
\hline 20 & Exon 10 & g.83283_83287del & tttcctttaac & p.S494X & ECL3 & Stop codon at position 494 \\
\hline \multirow[t]{2}{*}{$58^{8}$} & Exon 12 & $g .84724 \mathrm{G}>\mathrm{A}$ & caggagc & p. G545E & ICL2 & $\begin{array}{l}\text { Missense, possible effect on exonic splice } \\
\text { enhancers }\end{array}$ \\
\hline & Exon 13 & g.90996 C> T & tatcgac & p. $R 602 X$ & ICL3 & Nonsense mutation \\
\hline
\end{tabular}

bp = base pair; del= deletion; fs = frameshift; ins = insertion; IVS = intron; PTCH domains: ECLI = extracellular loop I; ECL2= extracellular loop 2; ICL3 = intracellular loop 3; TM2 = transmembrane 2; TM5 = transmembrane 5. aMutations are corrected for SNPs (using SNPs from blood samples for BCCs I- 12 and from SNP database for BCCs 13-20 and 58) b Numbering based on GenBank genomic DNA sequence ALI6|729. 'Applicable to exonic variants only. Protein numbering based on GenBank accession number NP_000255. 'Effect of intronic mutations on splicing was predicted using software at http://www.fruitfly.org/seq_tools/splice.html; effect of exonic mutations on exonic

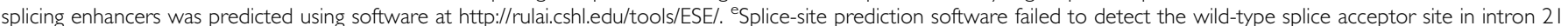
and, therefore, could not predict the effect of any of these variations on splicing. ${ }^{\mathrm{f}}$ This 16 -bp deletion deletes the last 4 bp of intron 8 and the first 12 bp of exon 9 . The deletion of 4 bp from intron 8 is predicted to have an effect on splicing. The in-frame deletion of 12 bp of exon 9 deletes four amino acids from the PTCH protein: $\mathrm{V} 406$, $\mathrm{V} 407, \mathrm{H} 408$ and Q409. 'Patient no. 58 is an organ transplant recipient never previously exposed to azathioprine. 
Table 3 PTCH mutations in BCC from azathioprine-exposed patients

\begin{tabular}{|c|c|c|c|c|c|c|}
\hline BCC ID & $\begin{array}{l}\text { Exon/intronic } \\
\text { position }\end{array}$ & $\begin{array}{l}\text { Variation in genomic } \\
\text { DNA }^{\text {a }}\end{array}$ & Sequence context & $\begin{array}{l}\text { Variation in } \\
\text { protein }^{b}\end{array}$ & $\begin{array}{l}\text { PTCH } \\
\text { domain }\end{array}$ & Effect $^{c}$ \\
\hline 21 & Exon 3 & g.7506। $C>T$ & tcatgatacagaccccta & p. Q160X & ECLI & Nonsense mutation \\
\hline 24 & Exon 20 & g. $101733-101734$ ins $A C$ & $\operatorname{agcACgtc}$ & p. VII37T fsX3 & TMII & Stop codon at position 1139 \\
\hline 28 & Exon 5 & g.7888। C>T & cgaaattacagtctggga & p. Q242X & ECLI & Nonsense mutation \\
\hline 30 & Exon 6 & g.80350 G>A & gctggga & p. W278X & ECLI & Nonsense mutation \\
\hline 33 & Exon 2 & g.54438 G>A & gtgggtg & p. WI29X & ECLI & Nonsense mutation \\
\hline 34 & Exon 14 & g.91901 G>T & tccgaga & p. E684X & ICL3 & Nonsense mutation \\
\hline 35 & IVS $2+1$ & 54446 del G & aaggtaa & - & - & Splicing \\
\hline 36 & Exon 22 & g. $11 \mid 703 \mathrm{G}>\mathrm{A}$ & tacgagg & p. EI242K & C-term & $\begin{array}{l}\text { Missense mutation; possible effect on exonic } \\
\text { splice enhancers predicted }\end{array}$ \\
\hline 38 & Exon 17 & g. $101078 \mathrm{C}>\mathrm{T}$ & tgactaaacagcgtctgg & p. Q905X & ECL2 & Nonsense mutation \\
\hline $39^{d}$ & Exon 15 & g.936I5 del G & cccgaat & p. N8|4|fsX|6 & ECL2 & Stop codon at position 829 \\
\hline 41 & Exon 15 & g.93622 C>T & atccagc & p. Q8I6X & ECL2 & Nonsense mutation \\
\hline \multirow[t]{2}{*}{44} & IVS7-2 & $g .81703 \mathrm{~A}>\mathrm{C}$ & $\operatorname{tgca} \mathbf{g c g}$ & - & - & See below ${ }^{e}$ \\
\hline & IVS7-I & g.8I704 G>T & $\operatorname{tgca} \mathbf{g c g}$ & - & - & See below ${ }^{\mathrm{e}}$ \\
\hline 48 & IVS8-6 & g.82660 C > T & tgaccac & - & - & No effect on splicing predicted \\
\hline 51 & Exon 18 & |0258| del G & cgagtat & p. E970D fs $\times 25$ & ECL2 & Stop codon at position 994 \\
\hline \multirow[t]{2}{*}{53} & Exon 23 & g. II $3735 \mathrm{C}>\mathrm{T}$ & tcgccgt & p. Al380V & C-term & $\begin{array}{l}\text { Missense mutation; possible effect on exonic } \\
\text { splice enhancers predicted }\end{array}$ \\
\hline & Exon 10 & $g .83158 \mathrm{~T}>\mathrm{G}$ & tcatgct & p. $Y 452 X$ & TM2 & Nonsense mutation \\
\hline 54 & Exon 3 & g.75076 G>T & gaagaag & p. El65X & ECLI & Nonsense mutation \\
\hline \multirow[t]{5}{*}{56} & IVSI I-I & g.84692 G>A & ccaggac & - & - & Splicing \\
\hline & Exon 17 & g. $101230 \mathrm{C}>\mathrm{A}$ & ctacatg & p. Y955X & ECL2 & Nonsense mutation \\
\hline & IVS2I- | | & g. $11|5| 8 \mathrm{C}>\mathrm{T}$ & atcccct & - & - & See below ${ }^{f}$ \\
\hline & IVS2I-10 & g. $111519 \mathrm{C}>\mathrm{T}$ & $\begin{array}{l}\text { Single tandem } \\
\text { mutation }\end{array}$ & - & - & See below ${ }^{f}$ \\
\hline & Exon 15 & g.93597 C> T & cacccag & p. T807T & ECL2 & $\begin{array}{l}\text { Silent variant; possible effect on exonic splice } \\
\text { enhancers predicted }\end{array}$ \\
\hline \multirow[t]{2}{*}{57} & Exon 5 & g.7888| C>T & cgaaattacagtctggga & p. Q242X & ECLI & Nonsense mutation \\
\hline & Exon 13 & g.90996 C>T & tatcgac & p. $R 602 X$ & ICL3 & Nonsense mutation \\
\hline \multirow[t]{2}{*}{$29^{\circ}$} & IVS20+I & g. 107375 G>A & caggtaa & - & - & Splicing \\
\hline & Exon 6 & g.80326_80335 del & agaaaataaactatca & p. K270Ifs $\times 10$ & ECLI & Stop codon at position 279 \\
\hline $45^{g}$ & $|V S 2|+5$ & g. $11101 \overline{6} \mathrm{G}>\mathrm{A}$ & tcagtag & - & - & See below ${ }^{d}$ \\
\hline $47^{g}$ & IVS7+ I & g.80884 G>A & caggtaa & - & - & Splicing \\
\hline
\end{tabular}

del=deletion; fs =frameshift; ins=insertion; IVS=intron; PTCH domains: $E C L I=$ extracellular loop I; ECL2=extracellular loop 2; ICL3=intracellular loop 3 ; TM2 = transmembrane 2; TMI I = transmembrane II. "Numbering based on GenBank genomic DNA sequence ALI61729 available at http://www.ncbinlm.nih.gov/entrez/ viewer.fcgi?val = ALI61729.27. Mutations are corrected for SNPs using SNPs from blood samples (BCCs 22-39, 48, 49 and 57) and from SNP databases (BCCs 21, 40-47, $50-56,58-60)$. ${ }^{\text {b}}$ Applicable to exonic variants only. Protein numbering based on GenBank accession number NP_000255. 'Effect of intronic mutations on splicing was predicted using software at http://www.fruitfly.org/seq_tools/splice.html; effect of exonic mutations on exonic splicing enhancers was predicted using software at http://rulai.cshl.edu/tools/ ESE/. In sample 39, the genomic variation CI I3540T in exon 23 (c. 3944 c > T) was detected in tumour tissue but not in blood. As this is a common SNP, it was not included

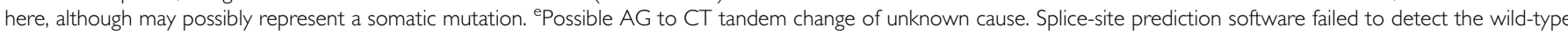
splice acceptor site in intron 7 and, therefore, could not predict the effect of this variation on splicing. However, as both of these variations are in the intron 7 splice acceptor site, they are likely to have an effect on splicing. SPplice-site prediction software failed to detect the wild-type splice acceptor site in intron 21 and, therefore, could not predict the effect of any of these variations on splicing. ${ }^{9}$ Patient nos. 29,45 and 47 had previously been exposed to azathioprine, but not for 2 years before the removal of BCC (see table 2 for details).

The proportion of exonic and intronic mutations was similar in the two groups; intronic mutations accounted for 6 out of $17(35 \%)$ mutations in the non-Aza group and 9 out of $27(33 \%)$ mutations in the Aza group (Table 4). Analysis of mutation distribution over the predicted PTCH protein structure (www.cybergene.se/PTCH/) identified no significant differences between the Aza and non-Aza groups. Extracellular loop domains were the most commonly mutated sites in both the groups accounting for 13 out of $18(72 \%)$ exonic mutations in the Aza group and 6 out of 11 (55\%) in the non-Aza group. Table 4 summarises the distribution of mutations on the PTCH protein domains.

Nonsense and stop mutations were the most frequently observed PTCH mutations, together accounting for 8 out of $17(47.1 \%)$ and 15 out of $27(55.6 \%)$ mutations in non-Aza $v s$ Aza group, respectively.

\section{PTCH mutation spectra in BCC from azathioprine- and non-azathioprine-exposed patients}

PTCH mutations in azathioprine-exposed patients PTCH mutations were detected in 21 out of $39(54 \%)$ BCCs from OTRs exposed to azathioprine (Table 3). Seventeen (81\%) had a single mutation and the remainder had between two and four mutations each. Of the 27 individual mutations, there were $12(44.4 \%)$ transitions at dipyrimidine sites, consistent with UVB involvement. A further three mutations (11.1\%) were G:C to T:A transversions generally regarded to reflect oxidative damage in the form of unrepaired DNA 8-oxoguanine. There were five (18.5\%) deletions or insertions, all at non-repetitive sequences. We also observed four (14.8\%) G:C to A:T transitions at nondipyrimidine sites (Figure 1). These unusual mutations occurred in samples 21, 28, 38 and 57 from three patients who were receiving only prednisolone and azathioprine. Strikingly, although each mutation was at a different locus in the $P T C H$ gene in each individual, they shared an identical TGTC sequence context (Figure 2). Two of these mutations occurred in apparently independent superficial BCCs (samples 28 and 57, Table 3) that developed in close proximity on the trunk of a single patient. It is possible that these were, in fact, contiguous regions of a single superficial tumour, the entirety of which was not clinically apparent. Nevertheless, we have considered these clinically distinct tumours to be of independent origin. 
Table 4 Comparison of the overall PTCH mutation frequency, exon/ intron ratio and the distribution throughout the PTCH transmembrane protein.

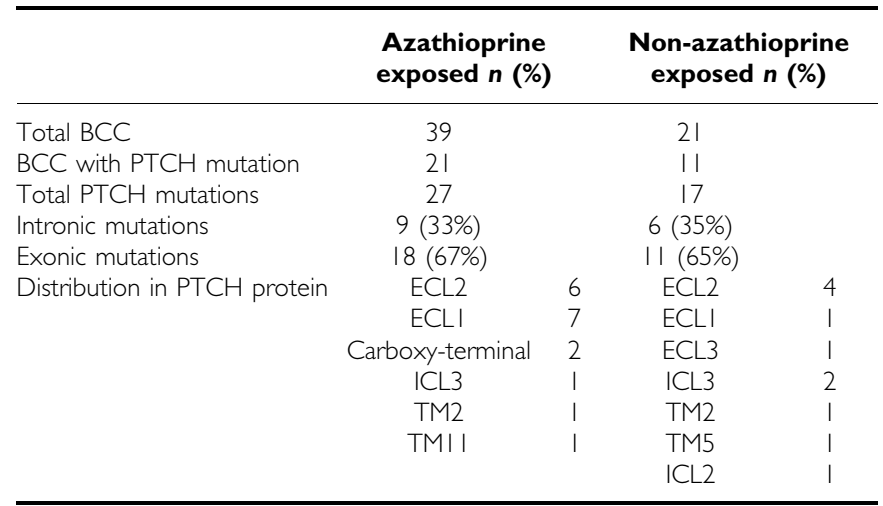

$\overline{E C L I}=$ extracellular loop I; ECL2 = extracellular loop 2; ECL3 = extracellular loop 3; $\mathrm{ICL} 3=$ intracellular loop 3; ICL2 = intracellular loop 2; $\mathrm{TM} 2=$ transmembrane 2; TM5 = transmembrane 5; TM $\mid$ | = transmembrane $\mid$ ।.

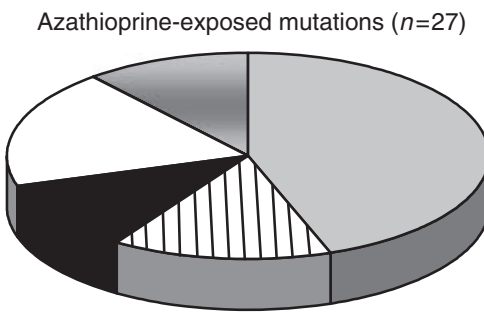

Non-azathioprine-exposed mutations $(n=17)$

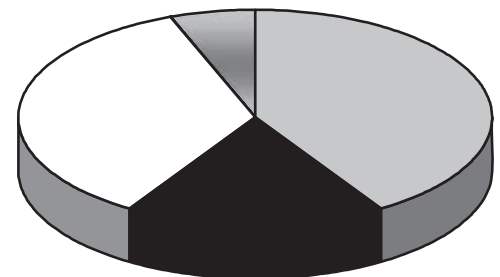

$\square$ UVB
$\square$ G:C>A:T at non-dipy site
$\square$ Oxidation
$\square$ Ins/del
$\square$ Other

Figure I PTCH mutation spectra in BCC from azathioprine- and nonazathioprine-treated patients. A similar proportion of UVB and oxidationtype mutations is present in each group. The G:C to $A: T$ transition mutations at non-dipyrimidine sites (hatched) occured exclusively in the azathioprine-exposed group. These were all within the same TGTC sequence in different locations within $\mathrm{PTCH}$

PTCH mutations in non-azathioprine-exposed patients PTCH mutations were identified in 12 out of 21 (57.1\%) BCCs from patients never treated with azathioprine (20 IC individuals and one OTR) (Table 2). Seven of these tumours (58.3\%) contained a single mutation and five each contained two. Of the 17 individual mutations, seven (41.2\%) UVB signatures at dipyrimidine sites comprised the largest single group. Three (17.6\%) were G:C to T:A transversions, indicating a similar frequency of oxidation-related mutations as in the Aza group. There were six (35.3\%) deletions of between 1 and 10 bases in moderately repetitive or non-repetitive sequences. We did not observe any of the G:C to A:T transitions at non-dipyrimidine sites that were found in the Aza group (Figure 1).

To examine the possible cumulative effects of azathioprine treatment on mutation type, the Aza-treated group was divided into two subgroups, having received greater or less than 120 months of azathioprine treatment. Of 15 mutations in the group exposed for less than 120 months, 8 were UVB type. Among those
A
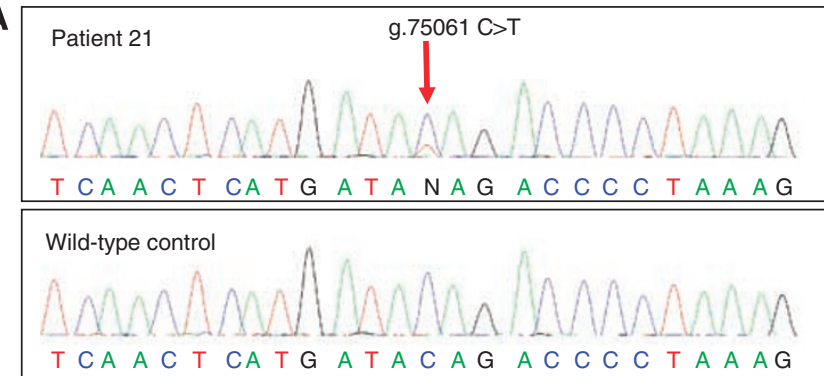

B
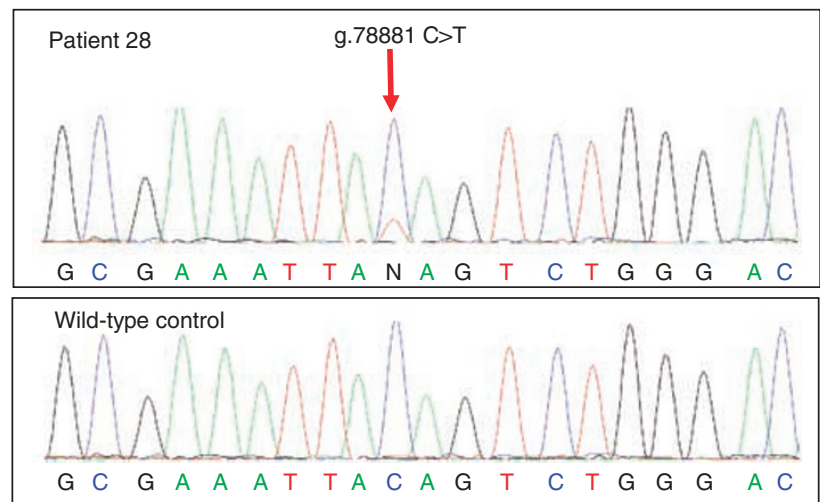

Figure 2 Sequencing data in BCC from azathioprine-exposed individuals. (A) Mutation in PTCH exon 3 (g.7506I C>T, c.478 C>T, p. Q I60X). Data from patient BCC ID 21 (top) and from a wild-type control (bottom). (B) Mutation in PTCH exon 5 (g.7888। C>T, c. 724 C>T, p. Q242X). Sequencing data are from patient BCC ID 28 (top) and from a wild-type control (bottom).

more extensively exposed ( $>120$ months) there were 4 (of 12). The difference in UVB-type mutations between the two groups is not statistically significant $(P$-value $=0.571$; adjusted for sun exposure, sex and clustering within individuals). Three of the four G:C to A:T transition mutations at non-dipyrimidine sites, exclusive to the azathioprine-exposed group, were in patients exposed for $>120$ months.

\section{The effect of additional immunosuppressants}

PTCH mutations were equally frequent in BCCs from patients exposed to azathioprine and prednisolone (7 out of $15,47 \%$ BCC) and in the group treated with ciclosporin in addition to azathioprine and prednisolone (14 out of $24,58.3 \%$ BCC). At the time of tumour removal, two patients in the ciclosporin and Aza group had discontinued prednisolone. The majority of mutations in the group exposed to all three immunosuppressants were of the UVB type (11 out of $19,57.9 \%$ individual mutations). In the azathioprine plus prednisolone group, only one of eight $(12.5 \%)$ mutations was a UVB type and this group contained all four of the $\mathrm{G}: \mathrm{C}$ to A:T transitions at non-dipyrimidine sites. The apparently lower frequency of UVB-type mutations in the azathioprine/ prednisolone group may simply reflect the imbalance between SE and NSE BCCs in the two groups as six (of eight) individual mutations in the azathioprine/prednisolone group were from BCCs on NSE sites.

\section{PTCH mutations and sun exposure}

Although the involvement of UVB mutagenesis in PTCH of BCCs from IC individuals has previously been reported, nothing is known about the role of UVB in BCC from azathioprine-treated patients. To address the latter point, we specifically examined 
PTCH mutations in BCCs from chronically SE sites. In addition, as BCCs are more common on NSE skin in OTR than in IC individuals, it is plausible that the effects of immunosuppressants are more apparent in the absence of chronic UVB exposure. To increase the chances of detecting azathioprine-related mutations, we therefore chose to examine more NSE BCC from the Aza group (the ratio of SE to NSE tumours in the Aza group was approximately $1: 1$ compared with $4: 1$ in the non-Aza group).

Of the 60 BCCs analysed, 37 had occurred on SE sites. Of these, 20 were from azathioprine-treated patients and 17 from non-Aza patients. PTCH mutations occurred at similar frequencies in the two groups (60 and $70.6 \%$, respectively). As expected, UVB mutations were the largest single mutational class in the non-Aza BCC and one or more mutations of this type were found in 6 out of 12 (50\%). Ultraviolet-B mutations were also the predominant class in azathioprine-treated patients and were found in 9 out of 12 (75\%) BCC in this group.

There were only four NSE BCCs from the IC patients, none of which contained a mutated PTCH. Of the 37 BCCs in the azathioprine-treated group, 19 were from NSE skin. Nine (47.4\%) of these NSE BCCs contained a PTCH mutation but only one was a UVB type. In contrast, $C$ to $T$ transitions at nondipyrimidine sites in a TGTC sequence comprised almost half (four out of nine) of the mutations in this azathioprine-treated group. The significant $(P=0.02)$ over-representation of these mutations in NSE BCC suggests that they are unrelated to sunlight exposure and this route to $\mathrm{PTCH}$ inactivation is more likely in BCC on NSE skin of azathioprine-treated patients in which the contribution of UVB is minimised.

\section{Discussion}

To our knowledge, PTCH mutations in BCCs from immunosuppressed OTR have not previously been systematically investigated. PTCH was mutated in around half (55\%) of the BCCs examined, and this was independent of immune status and azathioprine treatment. This frequency is comparable with the known PTCH mutation frequency in BCCs from the general population. A recent comprehensive study (Heitzer et al, 2007) found PTCH to be mutated in 29 out of 60 tumours (48\%). We carried out a metaanalysis of 11 studies in BCCs from presumed IC individuals published between 1996 and 2007 (Gailani et al, 1996; Hahn et al, 1996; Johnson et al, 1996; Unden et al, 1996; Wolter et al, 1997; Aszterbaum et al, 1998; Ratner et al, 2001; Zhang et al, 2001; Kim et al, 2002; Reifenberger et al, 2005; Heitzer et al, 2007). This revealed that 105 out of $247(42.5 \%)$ tumours had at least one defined PTCH mutation. It appears that $P T C H$ mutation occurs at a similar high frequency in BCCs from both IC and immunosuppressed individuals.

The contribution of high-intensity sunlight exposure to BCC development in the general population is well established (Pelucchi et al, 2007). Compelling evidence for the involvement of UVB radiation comes from the prevalence of transitions at dipyrimidine sites that are generally regarded as signature UVB mutations. Heitzer et al, report that almost $70 \%$ of exonic $P T C H$ mutations in sporadic BCC were of this type. This incidence of UVB signature mutations is somewhat higher than the frequencies reported in other studies. Our meta-analysis, while confirming the high frequency of $P T C H$ mutations, revealed that UVB-type mutations were present in half (51.4\%) of the BCCs. Our analysis of BCC from immunosuppressed OTR demonstrated that UVB signatures were the predominant mutational class and comprised almost half of all PTCH mutations in the azathioprine-exposed $(44.4 \%)$ group. The frequency was the same $(41.2 \%)$ in the non-azathioprine-treated control group. These combined data affirm the relative genetic homogeneity of sporadic BCC of diverse clinical phenotype, the predominant causative role of UVB-induced DNA damage and the relatively minor contribution of oxidative DNA damage.

There are differences in the anatomical distribution of BCCs in immunosuppressed OTRs and those in the general population. Both develop head and neck lesions, but OTRs also have BCCs on relatively NSE skin, particularly the trunk and limbs (Kanitakis et al, 2003; Harwood et al, 2006). This has previously been attributed, at least in part, to ascertainment bias as OTRs are regularly systematically examined in dedicated transplant clinics. However, it may reflect the presence of another carcinogen that would be supported by the PTCH mutation analysis in this series.

The frequency of PTCH mutations in BCCs from NSE skin of azathioprine-treated patients was similar to that in BCC overall, but there were quantitative and qualitative differences in the mutational spectrum that we observed. UV-type mutations were under-represented, consistent with a lesser role for UVB on sites receiving either no, or only intermittent, sun exposure. In addition, we found an unusual class of apparently sequence-related nondipyrimidine site transitions in some of these OTR BCCs that could represent a mutational footprint associated with immunosuppressant (presumed Aza) treatment. We acknowledge that in addition to azathioprine, all patients in the organ transplant group had also been treated with prednisolone and, in many cases, ciclosporin. There is little evidence that corticosteroids are mutagenic (IARC Monographs: Prednisolone, 1987) but ciclosporin is a recognised human carcinogen (IARC Monographs: Ciclosporin, 1990). We note, however, that the spectrum of PTCH mutations in BCCs from our patients taking ciclosporin is closely similar to that for BCCs in non-immunosuppressed patients.

Our meta-analysis of 247 sporadic BCCs from patients not receiving azathioprine compared with our own findings suggests that the frequency of the non-dipyrimidine site transition is increased by azathioprine treatment. It was present in 4 out of 266 vs 3 out of 37 individuals in the non-Aza and Aza groups, respectively $(P=0.042$; Fisher's exact test). In addition, the unusual class of mutations was found in patients whose BCCs had developed after prolonged Aza exposure, suggesting that it may be dose related.

Azathioprine, and the related 6-mercaptopurine and 6-TG, have been in clinical use for more than 50 years. They are not powerful mutagens or carcinogens, although the incorporation of 6-TG in place of G in DNA is potentially weakly promutagenic. Substantial substitution of DNA G by 6-TG is well tolerated by cells and DNA 6 -TG is not significantly miscoding during replication. The - $\mathrm{SH}$ group of $6-\mathrm{TG}$ is, however, chemically reactive and cellular DNA 6-TG can become methylated or oxidised. Although likely to be produced only at low levels, the products of these chemical reactions $-S^{6}$-methyl-TG $\left(S^{6}\right.$-meTG) and $\mathrm{GSO}_{3}$ - are potentially highly mutagenic. The former miscodes during replication and directs the incorporation of A-a promutagenic change. Guanine6-sulphonate is a severe block to replication and may require the recruitment of error-prone DNA polymerases to effect bypass (O'Donovan et al, 2005; Zhang et al, 2007).

In cultured cells, 6-TG/UVA treatment is associated with an increased frequency of the G:C to C:G transversions (O'Donovan, 2006) consistent with oxidation (Henderson et al, 2003). As keratinocytes from patients treated with azathioprine contain measurable DNA 6-TG and their skin is selectively UVA sensitive (Perrett et al, 2008), we anticipated an increase in oxidation-type PTCH mutations in BCC from azathioprine-treated patients. We did not observe this. The reasons for this are unclear, but a contributory factor may be the relative anoxia of keratinocytes compared with cultured cells.

This study of PTCH mutation in BCC from azathioprine-treated organ transplant patients and IC individuals confirms that $P T C H$ is a major target for inactivation of diverse clinical types in BCC. The findings demonstrate that the major contribution of UVB radiation to the inactivation of $\mathrm{PTCH}$ in BCC on chronically SE skin is also 
evident in azathioprine-immunosuppressed patients. Our data also raise the novel possibility of a different aetiology for azathioprine-related BCC developing on areas of skin that generally receive intermittent or no exposure to sunlight. Basal cell carcinomas arising from NSE skin occur infrequently in IC patients (Kanitakis et al, 2003) and our panel of BCC included only four examples. None of these contained a PTCH mutation that precluded direct comparison of mutations between IC and azathioprine-treated patients. Furthermore, in our meta-analysis of BCC from IC patients, the anatomical site of the BCC was frequently not identified and the number of mutations from BCC on unequivocally NSE sites was again too small $(n=10)$ to allow meaningful comparison. It will be important for the significance of future studies to ensure that sufficient samples from IC patients are included.

It seems appropriate to follow up the hypothesis that azathioprine contributes to mutation in BCC from NSE areas with a more extensive study. The TP53 gene represents an alternative to $P T C H$ as a mutational target. TP53 is mutated in many sporadic BCCs and a large majority of reported mutations are UVB type (Brash et al, 1991; Giglia-Mari and Sarasin, 2003; Reifenberger et al, 2005). The IARC TP53 Somatic Mutation database lists more than 1000 mutations from normal, preneoplastic and neoplastic skin (Petitjean et al, 2007) although an association with immunosuppression is noted in only 26 cases for which the medication is

\section{REFERENCES}

Ashton KJ, Carless MA, Griffiths LR (2005) Cytogenetic alterations in nonmelanoma skin cancer: a review. Genes Chromosomes Cancer 43: $239-248$

Aszterbaum M, Rothman A, Johnson RL, Fisher M, Xie J, Bonifas JM, Zhang X, Scott MP, Epstein Jr EH (1998) Identification of mutations in the human PATCHED gene in sporadic basal cell carcinomas and in patients with the basal cell nevus syndrome. J Invest Dermatol 110: $885-888$

Bale AE, Yu KP (2001) The hedgehog pathway and basal cell carcinomas. Hum Mol Genet 10: $757-762$

Brash DE, Rudolph JA, Simon JA, Lin A, McKenna GJ, Baden HP, Halperin AJ, Ponten J (1991) A role for sunlight in skin cancer: UV-induced p53 mutations in squamous cell carcinoma. Proc Natl Acad Sci USA 88: $10124-10128$

Cui C, Elsam T, Tian Q, Seykora JT, Grachtchouk M, Dlugosz A, Tseng H (2004) Gli proteins up-regulate the expression of basonuclin in basal cell carcinoma. Cancer Res 64: $5651-5658$

Dahmane N, Lee J, Robins P, Heller P, Ruiz i Altaba A (1997) Activation of the transcription factor Gli1 and the Sonic hedgehog signalling pathway in skin tumours. Nature 389: $876-881$

de Gruijl FR (1999) Skin cancer and solar UV radiation. Eur J Cancer 35: 2003-2009

Dlugosz A, Merlino G, Yuspa SH (2002) Progress in cutaneous cancer research. I Investig Dermatol Symp Proc 7: 17-26

Eichberger T, Regl G, Ikram MS, Neill GW, Philpott MP, Aberger F, Frischauf AM (2004) FOXE1, a new transcriptional target of GLI2 is expressed in human epidermis and basal cell carcinoma. J Invest Dermatol 122: $1180-1187$

Euvrard S, Kanitakis J, Claudy A (2003) Skin cancers after organ transplantation. N Engl J Med 348: 1681-1691

Gailani MR, Stahle-Backdahl M, Leffell DJ, Glynn M, Zaphiropoulos PG, Pressman C, Unden AB, Dean M, Brash DE, Bale AE, Toftgard R (1996) The role of the human homologue of Drosophila patched in sporadic basal cell carcinomas. Nat Genet 14: 78-81

Giglia-Mari G, Sarasin A (2003) TP53 mutations in human skin cancers. Hum Mutat 21: $217-228$

Hahn H, Wicking C, Zaphiropoulous PG, Gailani MR, Shanley S, Chidambaram A, Vorechovsky I, Holmberg E, Unden AB, Gillies S, Negus K, Smyth I, Pressman C, Leffell DJ, Gerrard B, Goldstein AM, Dean M, Toftgard R, Chenevix-Trench G, Wainwright B, Bale AE (1996) Mutations of the human homolog of Drosophila patched in the nevoid basal cell carcinoma syndrome. Cell 85: $841-851$ not specified. We are unable to locate any publications that specifically address TP53 mutation spectra directly in relation to azathioprine exposure. In view of our findings with $\mathrm{PTCH}$, it now seems fitting to examine whether promutagenic effects of azathioprine contribute to TP53 mutation in BCC in areas of the skin that are protected from sunlight.

\section{ACKNOWLEDGEMENTS}

We are most grateful to Dr David Mesher and Professor Peter Sasieni, Centre for Epidemiology, Mathematics and Statistics, Bart's and the London Queen Mary's School of Medicine and Dentistry, Charterhouse Square, London, for their statistical advice. We also thank Dr Karin Purdie for her assistance with sample preparation. All authors are supported by Cancer Research UK. CM Perrett was also supported by a grant from the AICR.

\section{Conflict of interest}

The authors have no conflicts of interest to declare.

Supplementary Information accompanies the paper on British Journal of Cancer website (http://www.nature.com/bjc)
Harwood CA, Proby CM, McGregor JM, Sheaff MT, Leigh IM, Cerio R (2006) Clinicopathologic features of skin cancer in organ transplant recipients: a retrospective case-control series. J Am Acad Dermatol 54: $290-300$

Heitzer E, Lassacher A, Quehenberger F, Kerl H, Wolf P (2007) UV fingerprints predominate in the PTCH mutation spectra of basal cell carcinomas independent of clinical phenotype. J Invest Dermatol 127: $2872-2881$

Henderson PT, Delaney JC, Muller JG, Neeley WL, Tannenbaum SR, Burrows CJ, Essigmann JM (2003) The hydantoin lesions formed from oxidation of 7, 8-dihydro-8-oxoguanine are potent sources of replication errors in vivo. Biochemistry 42: $9257-9262$

International Agency for Research on Cancer (1987) IARC monographs on the evaluation of carcinogenic risks to humans. Azathioprine 26(Suppl 7) International Agency for Research on Cancer (1990) IARC monographs on the evaluation of carcinogenic risks to humans. Ciclosporin 50: 77

Ismail F, Mitchell L, Casabonne D, Gulati A, Newton R, Proby CM, Harwood CA (2006) Specialist dermatology clinics for organ transplant recipients significantly improve compliance with photoprotection and levels of skin cancer awareness. $\mathrm{Br} J$ Dermatol 155: 916-925

Johnson RL, Rothman AL, Xie J, Goodrich LV, Bare JW, Bonifas JM, Quinn AG, Myers RM, Cox DR, Epstein Jr EH, Scott MP (1996) Human homolog of patched, a candidate gene for the basal cell nevus syndrome. Science 272: $1668-1671$

Kanitakis J, Alhaj-Ibrahim L, Euvrard S, Claudy A (2003) Basal cell carcinomas developing in solid organ transplant recipients: clinicopathologic study of 176 cases. Arch Dermatol 139: 1133-1137

Karran P, Attard N (2008) Thiopurines in current medical practice: molecular mechanisms and contributions to therapy-related cancer. Nat Rev Cancer 8: 24-36

Kim MY, Park HJ, Baek SC, Byun DG, Houh D (2002) Mutations of the p53 and PTCH gene in basal cell carcinomas: UV mutation signature and strand bias. J Dermatol Sci 29: 1 -9

Lindstrom E, Shimokawa T, Toftgard R, Zaphiropoulos PG (2006) PTCH mutations: distribution and analyses. Hum Mutat 27: 215-219

McGregor JM, Berkhout RJ, Rozycka M, ter Schegget J, Bouwes Bavinck JN, Brooks L, Crook T (1997) p53 mutations implicate sunlight in posttransplant skin cancer irrespective of human papillomavirus status. Oncogene 15: 1737 - 1740

O'Donovan P (2006) Photochemical reactions of DNA 6-TG and their biological consequences. $\mathrm{PhD}$, The University of London, London 
O’Donovan P, Perrett CM, Zhang X, Montaner B, Xu YZ, Harwood CA, McGregor JM, Walker SL, Hanaoka F, Karran P (2005) Azathioprine and UVA light generate mutagenic oxidative DNA damage. Science 309: $1871-1874$

Oro AE, Higgins KM, Hu Z, Bonifas JM, Epstein Jr EH, Scott MP (1997) Basal cell carcinomas in mice overexpressing sonic hedgehog. Science 276: $817-821$

Pelucchi C, Di Landro A, Naldi L, La Vecchia C (2007) Risk factors for histological types and anatomic sites of cutaneous basal-cell carcinoma: an italian case - control study. J Invest Dermatol 127: 935-944

Perrett CM, Walker SL, O’Donovan P, Warwick J, Harwood CA, Karran P, McGregor JM (2008) Azathioprine treatment photosensitizes human skin to ultraviolet A radiation. Br J Dermatol 159(1): 198-204

Petitjean A, Mathe E, Kato S, Ishioka C, Tavtigian SV, Hainaut P, Olivier M (2007) Impact of mutant p53 functional properties on TP53 mutation patterns and tumor phenotype: lessons from recent developments in the IARC TP53 database. Hum Mutat 28: 622-629

Ponten F, Berg C, Ahmadian A, Ren ZP, Nister M, Lundeberg J, Uhlen M, Ponten J (1997) Molecular pathology in basal cell cancer with p53 as a genetic marker. Oncogene 15: 1059-1067

Purdie KJ, Lambert SR, Teh MT, Chaplin T, Molloy G, Raghavan M, Kelsell DP, Leigh IM, Harwood CA, Proby CM, Young BD (2007) Allelic imbalances and microdeletions affecting the PTPRD gene in cutaneous squamous cell carcinomas detected using single nucleotide polymorphism microarray analysis. Genes Chromosomes Cancer 46: 661-669

Queille S, Luron L, Spatz A, Avril MF, Ribrag V, Duvillard P, Hiesse C, Sarasin A, Armand JP, Daya-Grosjean L (2007) Analysis of skin cancer risk factors in immunosuppressed renal transplant patients shows high levels of UV-specific tandem CC to TT mutations of the p53 gene. Carcinogenesis 28: 724-731

Quinn AG, Sikkink S, Rees JL (1994) Basal cell carcinomas and squamous cell carcinomas of human skin show distinct patterns of chromosome loss. Cancer Res 54: 4756-4759

Ratner D, Peacocke M, Zhang H, Ping XL, Tsou HC (2001) UV-specific p53 and PTCH mutations in sporadic basal cell carcinoma of sun-exposed skin. J Am Acad Dermatol 44: 293-297

Reed GH, Wittwer CT (2004) Sensitivity and specificity of single-nucleotide polymorphism scanning by high-resolution melting analysis. Clin Chem 50: $1748-1754$

Regl G, Neill GW, Eichberger T, Kasper M, Ikram MS, Koller J, Hintner H, Quinn AG, Frischauf AM, Aberger F (2002) Human GLI2 and GLI1 are part of a positive feedback mechanism in Basal Cell Carcinoma. Oncogene 21: 5529-5539

Reifenberger J, Wolter M, Knobbe CB, Kohler B, Schonicke A, Scharwachter C, Kumar K, Blaschke B, Ruzicka T, Reifenberger G (2005) Somatic mutations in the PTCH, SMOH, SUFUH and TP53 genes in sporadic basal cell carcinomas. Br J Dermatol 152: $43-51$

Swann PF, Waters TR, Moulton DC, Xu YZ, Zheng Q, Edwards M, Mace R (1996) Role of postreplicative DNA mismatch repair in the cytotoxic action of thioguanine. Science 273: $1109-1111$

Teh MT, Blaydon D, Chaplin T, Foot NJ, Skoulakis S, Raghavan M, Harwood CA, Proby CM, Philpott MP, Young BD, Kelsell DP (2005) Genomewide single nucleotide polymorphism microarray mapping in basal cell carcinomas unveils uniparental disomy as a key somatic event. Cancer Res 65: 8597-8603

Teh MT, Wong ST, Neill GW, Ghali LR, Philpott MP, Quinn AG (2002) FOXM1 is a downstream target of Gli1 in basal cell carcinomas. Cancer Res 62: $4773-4780$

Ullrich SE (2005) Mechanisms underlying UV-induced immune suppression. Mutat Res 571: 185-205

Unden AB, Holmberg E, Lundh-Rozell B, Stahle-Backdahl M, Zaphiropoulos PG, Toftgard R, Vorechovsky I (1996) Mutations in the human homologue of Drosophila patched (PTCH) in basal cell carcinomas and the Gorlin syndrome: different in vivo mechanisms of $\mathrm{PTCH}$ inactivation. Cancer Res 56: $4562-4565$

Wicking C, Shanley S, Smyth I, Gillies S, Negus K, Graham S, Suthers G, Haites N, Edwards M, Wainwright B, Chenevix-Trench G (1997) Most germ-line mutations in the nevoid basal cell carcinoma syndrome lead to a premature termination of the PATCHED protein, and no genotype-phenotype correlations are evident. Am J Hum Genet 60: $21-26$

Wolter M, Reifenberger J, Sommer C, Ruzicka T, Reifenberger G (1997) Mutations in the human homologue of the Drosophila segment polarity gene patched (PTCH) in sporadic basal cell carcinomas of the skin and primitive neuroectodermal tumors of the central nervous system. Cancer Res 57: $2581-2585$

Xie J, Murone M, Luoh SM, Ryan A, Gu Q, Zhang C, Bonifas JM, Lam CW, Hynes M, Goddard A, Rosenthal A, Epstein Jr EH, de Sauvage FJ (1998) Activating Smoothened mutations in sporadic basal-cell carcinoma. Nature 391: $90-92$

Zhang H, Ping XL, Lee PK, Wu XL, Yao YJ, Zhang MJ, Silvers DN, Ratner D, Malhotra R, Peacocke M, Tsou HC (2001) Role of PTCH and p53 genes in early-onset basal cell carcinoma. Am J Pathol 158: $381-385$

Zhang X, Jeffs G, Ren X, O'Donovan P, Montaner B, Perrett CM, Karran P, $\mathrm{Xu} Y \mathrm{YZ}$ (2007) Novel DNA lesions generated by the interaction between therapeutic thiopurines and UVA light. DNA Repair (Amst) 6: $344-354$

Ziegler A, Jonason AS, Leffell DJ, Simon JA, Sharma HW, Kimmelman J, Remington L, Jacks T, Brash DE (1994) Sunburn and p53 in the onset of skin cancer. Nature 372: 773-776 